\title{
RESEARCHES IN QUALITY OF DRIED AND CHOPPED CHICORY HERB SORTING PROCESS
}

\author{
Augustina Pruteanu \\ National Institute of Research-Development for Machines and Installations \\ Designed to Agriculture and Food Industry, Romania \\ pruteanu_augustina@yahoo.com
}

\begin{abstract}
Romania's natural potential is immense: out of the 3,700 species of plants growing in our country, the medicinal flora is represented by 800 species, of which 370 certainly have therapeutic properties for treating various diseases. The same medicinal species may have multiple effects on the human body due to the complexity of the component bioactive substances that act simultaneously on different physiological processes or states. The processing of medicinal plants is conditioned by the improvement of technologies, as well as the development of the technical base of specific machinery and equipment, especially the ones for separating on dimensional classes, from which extracts rich in bioactive substances will be obtained. The dimensional uniformity of the classes, out of which plant extracts are obtained, must present the advantages of easier processing, storage and marketing in optimum conditions. For the separation of medicinal plants resulting from their harvesting, drying and chopping in bulk, specific equipment provided with separation blocks with oscillating sieves has been developed and built. The paper presents the quality of the sorting process expressed by the degree of separation on sorts of different sizes of dried and chopped chicory herb (Cichorum intybus). The experimental researches were conducted on a chopped plant sorter, using oscillating plane sieves with different mesh sizes, different feed rates $\left(0.0166 \mathrm{~kg} \cdot \mathrm{s}^{-1}, 0.0125 \mathrm{~kg} \cdot \mathrm{s}^{-1}, 0.0083 \mathrm{~kg} \cdot \mathrm{s}^{-1}\right)$ and different revolution speeds (1000 RPM, 900 RPM, 800 RPM) of the mechanism for actuating the sieves. The experimental results obtained from sorting the chicory herb were processed and interpreted using polynomial regression functions.
\end{abstract}

Keywords: chicory, herb, quality of sorting process, degree of separation.

\section{Introduction}

Cichorium intybus L. (Fig.1) is a biennial or perennial herb and is a native of Europe and Asia [1]; it is a member of the family Asteraceae and is an erect perennial herb, it is of different types depending on the flowers which are bright blue, white or pink. Cichorium intybus is about $80 \pm 90 \mathrm{~cm}$ in height. It has a fleshy taproot up to $75 \mathrm{~cm}$ in length. Its habitants are roadsides, railroads and waste grounds, the flowering period lasts from June to October [2].
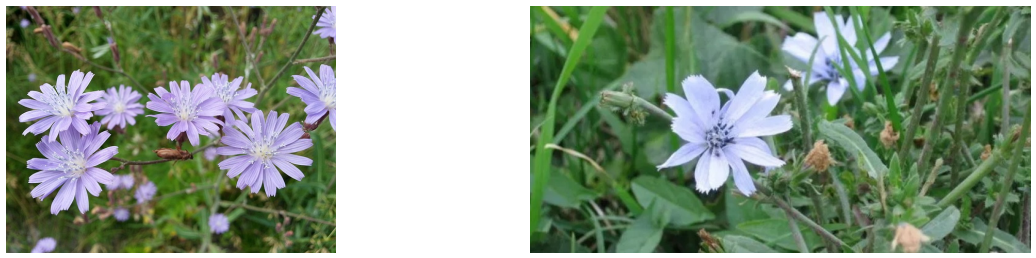

\section{Fig. 1. Chicory herb (Cichorum intybus) [4]}

Recent studies have found some of the important constituents in chicory, such as: flavonoids sesquiterpene lactones, caffeic acid derivatives, inulin, sugars, proteins, hydroxycoumarins, alkaloids, steroids, terpenoids, oils, volatile compounds, coumarins, vitamins, saponins, tannins. Leaves of the plant contain salts, such as sulphates and phosphates of sodium, magnesium and potassium as well as potassium nitrate. It also contains a bitter glycoside named cichorine [2;3;5].

In many industrial applications most of the solid particles are separated by size and for this purpose there are vibrating sieves used. The separation process based on sieves is a complex one and it depends on several factors, such as the properties of solid particles submitted to the separation process and on the operating regimes of the separating equipment [6].

In terms of structure, the technological process of primary manufacturing the medicinal plants represents that part of the manufacturing process, which comprises the totality of operations and intercorelated stages necessary to subsequently process the matter harvested or purchased [7].

Sorting is basically an assemblage of chances were particles encounter the sieve surface, and at each encounter there exists a likelihood of undersize particles passing through the sieve holes. It can also be defined as a process in which a screen surface acts as a barrier between oversize and undersize 
particles, in which in an ideal case undersize particles easily pass through, while oversize particles are retained, as shown in Figure 2. Undersize particles in this context refer to particles in a feed stream that are less than the sieve hole size and oversize particles as particles larger than the sieve hole size [8].

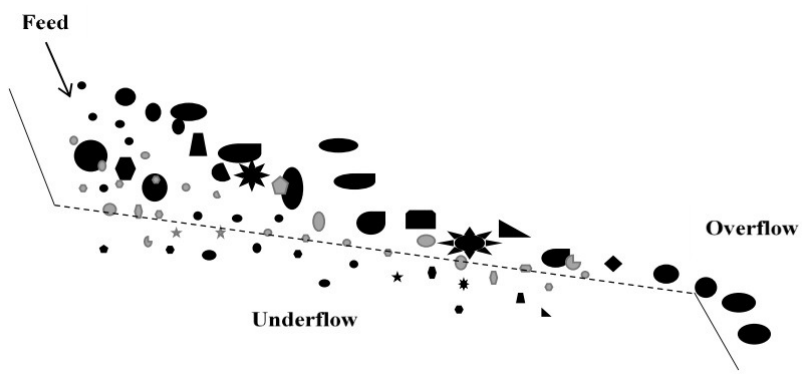

Fig. 2. Sorting process $[8]$

Many factors influence sorting of fine particles and can be grouped into design or machine factors and operational factors. Operational variables include the particle size distribution and shape, slurry density and viscosity, particle density, feed rate, material flowability and friability. Design or machine variables include the sieve hole shape and size, tilting angle, open area, sieve length and width, vibration intensity (frequency and amplitude) and material (herbs, grains, etc) of the sieve [8-10]. All these factors are adjusted during material recovery to minimise the effects of sieve blinding (occurs when undersize particles coagulate on the sieve surface and block the holes), hole plugging (happens when critical size particles get lodged in the holes) and material carryover (occurs when fine particles are carried over to the oversize stream) [8].

The sorting process needs to achieve the movment the separating materials must be in comparison with the sieve, or by sliding, or by jump. The materials, depending on the relation between their dimension and the sieve holes, can pass, or remain on the sieve, or fix in that, blocking it. The materials blocking the sieve holes are an obstacle for the sieving capacity, diminishing the real surface of separation and reducing the efficiency of the process. The danger of blocking the materials in sieve holes is so much less, as the inclination angle of the screen is bigger in comparison with the horizonal plane [11].

The current paper presents the experimental and theoretical researches related to obtaining the maximum sorting degree appropriate for chicory under certain conditions of work: sizes of the sieves holes, material feeding rate and the number of rotations of vibrating electric motors.

\section{Materials and methods}

The plant material used in the experiments, chicory (Cichorium intybus), was harvested from the spontaneous flora of Romania and identified by the morphological and biological characteristics $[12 ; 13]$ of the species.

The herb was dried naturally in the shade, until it reached the storage humidity (maximum $13 \%$ ), cleaned of foreign bodies (inorganic materials or other plants, injured parties) under the provisions of [14;15], and then chopped in bulk using the TIMATIC grinder for medicinal plants, adjusted to the size of $6 \mathrm{~mm}$.

The experimental researches were conducted on a dimensional sorting equipment for chopped plants (Fig. 3), existing in operation within INMA Bucharest, which technical specifications are presented in Table 1. This equipment is provided with 9 frames with sieves, having different hole sizes, used in sets of two or three, depending on the requirements [16].

Three feed rates were used in the experiments $\left(0.0166 \mathrm{~kg} \cdot \mathrm{s}^{-1}, 0.0125 \mathrm{~kg} \cdot \mathrm{s}^{-1}\right.$ and $\left.0.0083 \mathrm{~kg} \cdot \mathrm{s}^{-1}\right)$ and three revolution speeds of the mechanism for actuating the sieves (1000 RPM, 900 RPM and $800 \mathrm{RPM}$ ), the sieve tilting angle fix at $\alpha=13.33^{\circ}$, the amplitude of oscillations at $3 \mathrm{~mm}$, the duration of an experiment was 30 seconds. During the tests three wire sieves with square holes, disposed in increasing order according to the hole size, were used. The sieve hole size has been chosen after 
performing the dimensional analysis of chicory fragments chopped so that they were placed as it follows: 4.0-6.3-8.0 $\mathrm{mm}$.

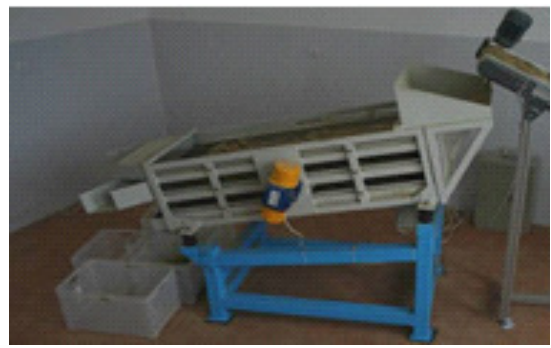

Fig. 3. Plant sorter

Table 1

Technical specifications of plant sorter [16]

\begin{tabular}{|l|c|}
\hline \multicolumn{1}{|c|}{ Characteristics of the equipment } & Measuring values \\
\hline Type of action & 2 vibrating electric motors \\
\hline Power of the electric motor & $0.15 \mathrm{~kW}$ \\
\hline Overall dimensions: & $2.330 \mathrm{~mm}$ \\
$\checkmark \quad$ length & $1.150 \mathrm{~mm}$ \\
$\checkmark \quad$ width & $1.530 \mathrm{~mm}$ \\
$\checkmark$ height & 3 \\
\hline Number of frames with sieves & $1.495 \mathrm{~mm}$ \\
\hline Sizes of sieve holes & $600 \mathrm{~mm}$ \\
\hline Frame dimensions with sieves & $40 \mathrm{~mm}$ \\
$\checkmark$ length & till $1000 \mathrm{RPM}$ \\
$\checkmark$ width & $1 \div 6 \mathrm{~mm}$ \\
\hline Revolution speed, $n$ & $12.08^{\circ} ; 13.33^{\circ} ; 14.7^{\circ}$ \\
\hline Amplitude of oscillations & $25-120 \mathrm{~kg} \cdot \mathrm{h}^{-1}$ \\
\hline Tilting the sieves in three fixed positions, $\alpha$ & $260 \mathrm{~kg}$ \\
\hline Sorting capacity & \\
\hline Equipment weight & \\
\hline
\end{tabular}

Degree of sorting $\left(\mathrm{G}_{\mathrm{s}}\right)$ is expressed in percentages $(\%)$ and is defined as the ratio between the quantity of fragments from each collecting box (sort I, sort II, sort III, sort IV) and the quantity of fragments from the four collecting boxes. Images of the four dimensional sorts are shown in Fig. 4.

Sort I contains vegetal fragments smaller than $4 \mathrm{~mm}$; Sort II contains vegetal fragments between 4.1-6.3 mm; Sort III contains vegetal fragments between $6.4-8.0 \mathrm{~mm}$ and Sort IV contains fragments bigger than $8.0 \mathrm{~mm}$.

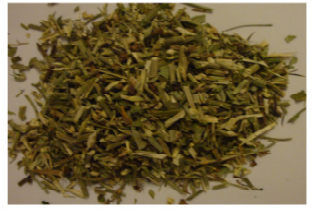

Sort I

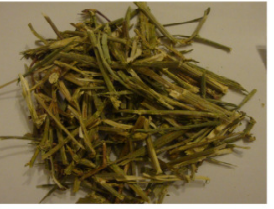

Sort II

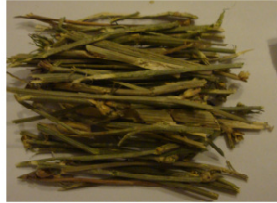

Sort III

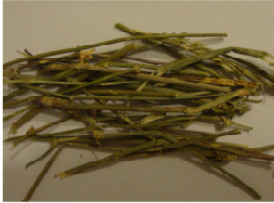

Sort IV

Fig. 4. Chicory fragments

The efficiency of Sort I is in obtaining beneficial phytotherapeutic preparations in treating various diseases $[1 ; 2 ; 3 ; 5]$.

Interpretation of the results was done for Sort I by the representation of functions of two variables, in which case the dependent variable (degree of sorting/separartion) is simultaneously a function of two independent variables, $\mathrm{x}_{1}=n$ respectively $\mathrm{x}_{2}=q$, resulting in polynomial functions of IInd degree with two variables, having the general form shown in equation $(1),[17 ; 18]$ : 


$$
f_{\left(x_{1}, x_{2}\right)}=a_{0}+a_{1} \cdot x_{1}+a_{2} \cdot x_{2}+a_{3} \cdot x_{1}^{2}+a_{4} \cdot x_{1} \cdot x_{2}+a_{5} \cdot x_{2}^{2},
$$

where $\quad x_{1}$-revolution speed $(n), \mathrm{RPM}$

$x_{2}$ - experimental flow $(q), \mathrm{kg} \cdot \mathrm{s}^{-1}$

$a_{0}, a_{1}, a_{2}, a_{3}, a_{4}, a_{5}$ - coefficients.

For processing of the experimental data the structure was used of a split testing experimental program, for 12 experiments, in Mathcad [17;20], given by the values of the independent variables ( $n$, $q$ ) and the values of the dependent variables $\left(\mathrm{G}_{\mathrm{s}}\right)$ from each experiment [17].

\section{Results and discussion}

The values of experimental data characterizing the sorting process by the sorter of 4 sorts (groups) of chicory are presented in Table 2.

Degree of sorting $\left(\mathrm{G}_{\mathrm{s}}\right)$ was calculated with the mass of fragments of Sort I and is presented in Table 2.

Table 2

Experimental results regarding the sorting of chicory fragments

\begin{tabular}{|c|c|c|c|c|c|c|c|c|c|}
\hline $\begin{array}{c}\text { Flow rate } \\
Q_{\text {alim }}, \\
\mathbf{k g} \cdot \mathbf{s}^{-1}\end{array}$ & $\begin{array}{c}\text { Revolution } \\
\text { speed } n \text {, } \\
\text { RPM }\end{array}$ & $\begin{array}{c}\text { Experim } \\
\text { ent num } \\
\text { ber }\end{array}$ & $\begin{array}{c}\text { Mass } \\
\text { sort } \\
\text { M1, kg }\end{array}$ & $\begin{array}{c}\text { Mass } \\
\text { sort } \\
\text { M2, kg }\end{array}$ & $\begin{array}{c}\text { Mass } \\
\text { sort } \\
\text { M3, kg }\end{array}$ & $\begin{array}{c}\text { Mass } \\
\text { sort } \\
\text { M4, kg }\end{array}$ & $\begin{array}{c}\text { Total } \\
\text { mass } \\
\mathrm{M}_{\mathrm{t}}, \mathrm{kg}\end{array}$ & $\begin{array}{c}\text { Experime } \\
\text { ntal flow, } \\
q, \mathrm{~kg}^{-\mathrm{s}^{-1}}\end{array}$ & $\begin{array}{c}\text { Degree of } \\
\text { sorting, Sort } \\
\text { I G }_{\mathrm{s}}, \%\end{array}$ \\
\hline \multirow{3}{*}{0.0166} & 1000 & 9 & 0.337 & 0.053 & 0.099 & 0.010 & 0.499 & 0.0166 & 67.54 \\
\hline & 900 & 6 & 0.339 & 0.047 & 0.098 & 0.007 & 0.491 & 0.0164 & 69.04 \\
\hline & 800 & 3 & 0.308 & 0.045 & 0.102 & 0.005 & 0.460 & 0.0153 & 66.96 \\
\hline \multirow{3}{*}{0.0125} & 1000 & 8 & 0.255 & 0.028 & 0.085 & 0.004 & 0.372 & 0.0124 & 68.50 \\
\hline & 900 & 5 & 0.230 & 0.026 & 0.085 & 0.004 & 0.345 & 0.0115 & 66.70 \\
\hline & 800 & 2 & 0.206 & 0.026 & 0.087 & 0.003 & 0.322 & 0.0107 & 63.90 \\
\hline \multirow{3}{*}{0.0083} & 1000 & 7 & 0.165 & 0.020 & 0.060 & 0.004 & 0.249 & 0.0083 & 66.27 \\
\hline & 900 & 4 & 0.167 & 0.019 & 0.057 & 0.004 & 0.247 & 0.0082 & 67.61 \\
\hline & 800 & 1 & 0.149 & 0.017 & 0.064 & 0.003 & 0.233 & 0.0078 & 63.95 \\
\hline
\end{tabular}

In order to determine the optimum sorting degree for Sort (group) I chicory, mathematical modelling in Mathcad program has been done, by which, after having imposed linear restrictions of $n$ and $q$ that showed the value interval of independent variables, the coefficients and form of polynomial function of II $^{\text {-nd }}$ degree with two variables were calculated.

Linear restriction values framed between a minimum value and a maximum value $[17 ; 18]$ :

$$
\begin{gathered}
800 \mathrm{RPM}=x_{1 \min \leq} x_{1}=n \leq x_{1 \max }=1000 \mathrm{RPM} \\
7.8 \mathrm{~kg} \mathrm{~s}^{-1}=x_{2 \min } \leq x_{2}=q \leq x_{2 \min }=16.6 \mathrm{~kg} \mathrm{~s}^{-1}
\end{gathered}
$$

Thus, it resulted the function and function coefficients replaced as $[17 ; 18]$ :

$$
G s_{(n, q)}=-76.953+0.291 \cdot n+1.229 \cdot q-1.46 \cdot 10^{-4} \cdot n^{2}-1.44 \times 10^{-3} \cdot n \cdot q-0.013 \cdot q^{2}
$$

After defining the normal equation system, the correlation coefficient $\mathrm{R}^{2}=0.915$ was calculated. Figure 5 presents the function's graphic. Figure 6 presents the experimental values of the sorting degree, comparing to the theoretical values, calculated by the polynomial regression function for each experiment.

In Figure 6 it can be noticed that the differences between the values experimentally obtained and those calculated for chicory sort I are small $0.05 \%$ for $n=900 \mathrm{RPM}$ and $q=0.0164 \mathrm{~kg} \mathrm{~s}^{-1}$ and big $1.22 \%$ for $n=1000 \mathrm{RPM}$ and $q=0.0124 \mathrm{~kg} \mathrm{~s}^{-1}$.

In the Matchad program 10 values were selected from the range of linear restrictions imposed for the experimental flow rate $(q)$ in Fig. 7 and the revolution speed $(n)$ in Fig. 8, resulting in the degree of sorting Sort I for each of the 10 values. These were represented graphically in the Excel program and correlated with the polynomial functions of the program. 

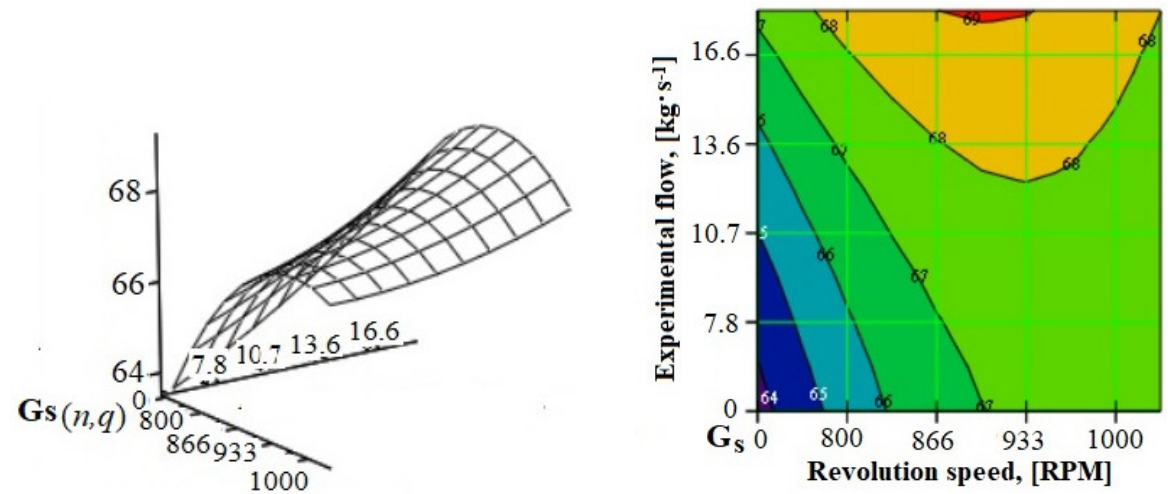

Fig. 5. Variation of chicory sorting degree according to revolution speed and experimental flow

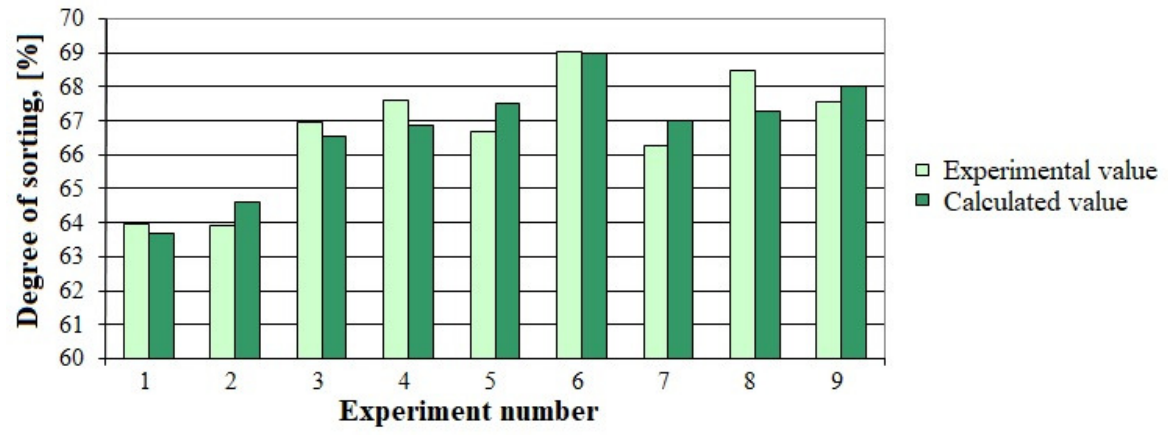

Fig. 6. Degree of sorting for sort I for chicory

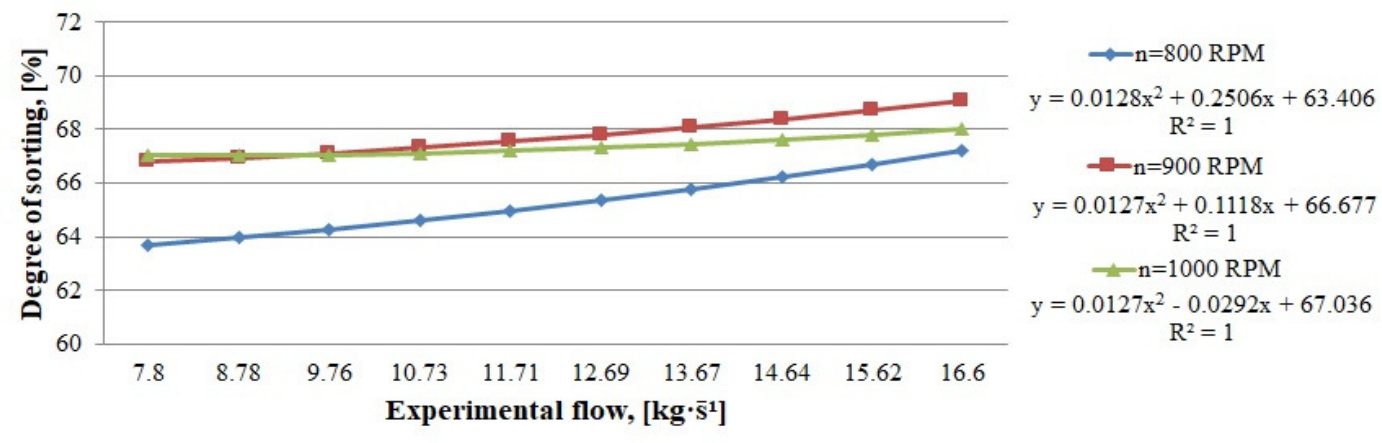

Fig. 7. Variation of sieve experimental flow rate for chicory

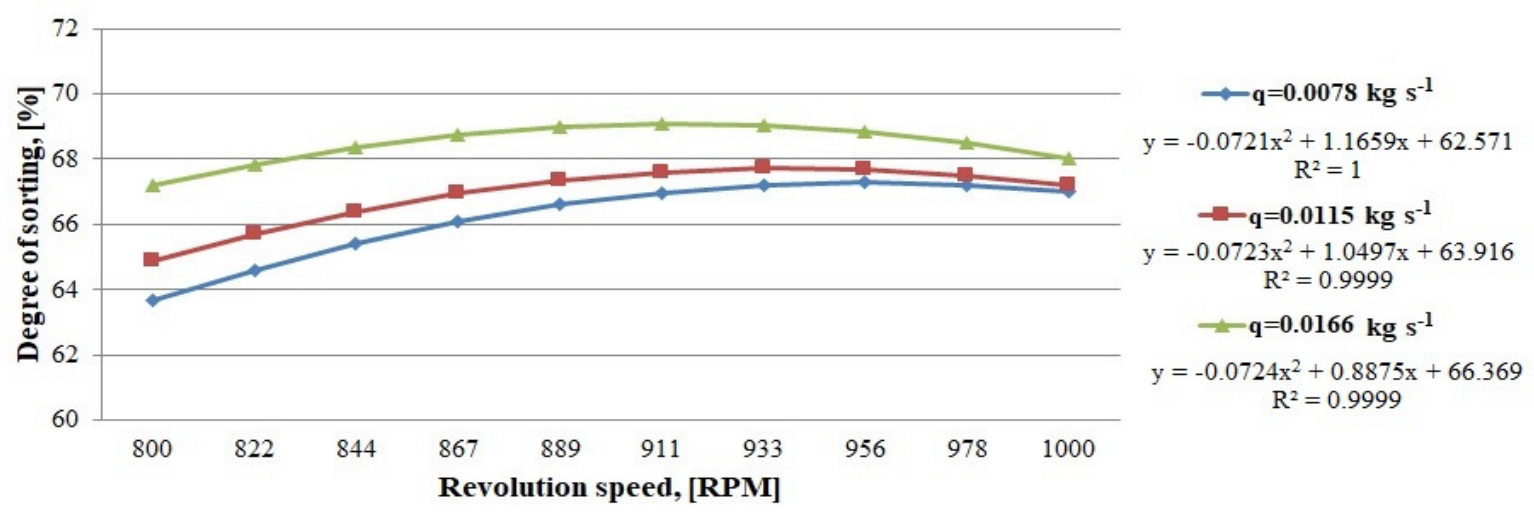

Fig. 8. Variation of sorting degree depending on sieve driving mechanism for chicory

It can be seen from Figures 7 and 8 that the polynomial functions correlate very well $\left(R^{2}=1\right)$. 
Similar results on the quality of sorting by other dimensional sorts (groups) of other medicinal herbs as nettle, thyme are found in [18], for rattles, mint, yarrow fresh and dried in [19].

\section{Conclusions}

1. Chicory dried and chopped in bulk at $6.0 \mathrm{~mm}$ was separated on sieves which hole size is growing, thus: 4.0-6.3-8.0 $\mathrm{mm}$; for the sieve tilting angle of $13.33^{\circ}$ the maximum value of the sorting degree was $G_{s \max }=69.04 \%$, for the values of independent variables: $n=900$ RPM and $q=0.0164 \mathrm{~kg} \cdot \mathrm{s}^{-1}$ and the minimum value is $G_{s \min }=63.90 \%$, for independent variables values: $n=800 \mathrm{RPM}$ and $q=0.0107 \mathrm{~kg} \cdot \mathrm{s}^{-1}$.

2. The values determined experimentally and calculated for Sort I of chicory are small $0.05 \%$ for $n=900 \mathrm{RPM}$ and $q=0.0164 \mathrm{~kg} \mathrm{~s}^{-1}$. Variation of the parameters chosen for the plant sorter has been correlated to polynomial function of II-degree with two variables, deviations being insignificant.

3. From the results obtained, the following optimal parameters are recommended for obtaining Sort I of chicory: the sieve tilting angle $13.33^{\circ}$, revolution speed 900 RPM, amplitude of oscillations $3 \mathrm{~mm}$, experimental flow $0.0164 \mathrm{~kg} \cdot \mathrm{s}^{-1}$.

4. Efficiency of chicory separation (Sort $\mathrm{I}=0.1-4.0 \mathrm{~mm}$ ) can be achieved at a high level, if the working regime parameters are appropriately selected, and separation of sorted plants with homogeneous dimensions is important for production of high-quality fytoterapeutics.

\section{Acknowledgements}

This work was supported by a grant of the Romanian Research and Innovation Ministry, through Programme 1 - Development of the national research-development system, subprogramme 1.2 Institutional performance - Projects for financing excellence in RDI, contract No. 16PFE.

\section{References}

[1] Tauseef S., Atar M., Khan W., Rub R. An overview on phytochemical and pharmacological profile of Cichorium intybus Linn, Pharmacologyonline 2, 2010, pp. 298-307.

[2] Zaman R., Basar S. N. A review article of beekhe kasni (Cichorium intybus) its traditional uses and pharmacological actions, Research Journal of Pharmaceutical Sciences, Vol. 2(8), 2013, pp. 1-4.

[3] Neha M., Deepshikha P. K., Vidhu A., Amitesh K., Vidushi J., Alka M., Ritu V. Determination of antioxidant and hepatoprotective ability of flavonoids of Cichorium intybus, International Journal of Toxicological and Pharmacological Research; 6(4), 2014, pp. 107-112.

[4] Ardelean A., Mohan Gh. Flora Medicinală a României, All Publishing, Bucharest, 2008. 268 p.

[5] Al-Snafi A. E. Medical importance of Cichorium intybus - A review, Volume 6, Issue 3, 2016, pp. 41-56.

[6] Bontas O., Nedeff V., Mosnegutu E. F., Panainte M., Tirtoacă Irimia O., Behaviour of solid particles on a flat oscillating surface, Environmental Engineering and Management Journal, Vol.12, No. 1, 2014, pp.17-22.

[7] Danciu A., Postelnicu E., Vlăduţ V., Voicea I., Matache M., Ludig M. Martinov M., Atanasov A., Florea C. Experimentation of technology and equipments for primary processing of medicinal and aromatic plants. Obtaining of extractive solutions from medicinal and aromatic plants, INMATEH-Agricultural Engineering, Vol. 34, No.2, 2011, Bucharest, pp. 57-66.

[8] Kabondo L. Determination of drainage rates of heavy media for different aperture sizes on a vibrating screen, Master of engineering, Faculty of Engineering at Stellenbosch University, 2018. $5,20,21 \mathrm{p}$.

[9] Oztekin S., Martinov M. Medicinal and aromatic crops: harvesting, drying and processing, Haworth Press Publishing, United States and Canada, 2007. 154-172 p.

[10] KeShun L. Some factors affecting sieving performance and efficiency, Powder Technology, Vol.193, Issue 2, Elsevier Publishing House, London, 2009, pp.208-213.

[11]Ene Gh. About the sieving process of vibratory screen, The Scientific Bulletin of Valahia University - Materials and Mechanics, No. 5, 2010, pp. 154-156. 
[12] Chifu T., Mânzu C., Zamfirescu O., Şurubaru B. Guide for practical works of Systematic Botany, Univ. "Al.I.Cuza" Publishing, Iaşi, 2002.

[13] Ciocârlan V., Illustrated Flora of Romania, Ceres Publishing, Bucharest, 2000.

[14] Romanian Pharmacopoeia, 10th edition, Medical Publishing, 1993.

[15]European Pharmacopoeia, 8th edition, EDQM Council of Europe Publishing, Strassbourg, 2011.

[16] Technical book of plant sorter, INMA Bucharest.

[17] Păunescu I., David L. Experimental research bases of biotechnical systems, Printech Publishing, Bucharest, 1999. 37-42 p.

[18] Pruteanu A., Vlăduț V., Matache M., Nițu M. Experimental researches on the quality of sorting process of medicinal plants, 46 Symposium "Actual Tasks on Agricultural Engineering”, Opatija, Croatia, 2018, 473-484 p.

[19] Florea Constanţa - C. Contributions to the improvement of technology and equipment for conditioning of medicinal plants and forest fruits before processing, $\mathrm{PhD}$ thesis, Transilvania University, Braşov, 2013.

[20] Mathcad Professional - User's guide with reference manual, United States of America 2001, [online][16.02.2019] Available at: www.mathsoft.com. 